\title{
Chitosan Based Films Incorporated with Turmeric/Clove/Ginger Essential Oil for Food Packaging
}

\author{
Yashaswini M, Iyer PR* \\ Department of Biotechnology, Women`s Christian College, Chennai, India
}

\begin{abstract}
The aim of this work was to produce chitosan based films which can be used as an effective packaging material. In order to produce a material like that chitosan was extracted from the crab shells by the process of demineralization, deproteinization and deacteylation and the obtained chitosan was made into a film with additives like Turmeric/ Clove/Ginger and gelatin. Plasticizer like glycerol was also added to obtain a transparent, stretchable, exquisite film which is a active packaging material and the film forming solution was used as a coating over the areca nut plates and cups to prevent the microbial spoilage and to increase the shelf life of them and then coating was also performed on fruits and vegetables to prevent spoilage and increase their shelf life. The film was checked for its thickness, transparency and stability. The physical, chemical and biological parameters were evaluated by performing the characterization studies like SEM, TG-DSC, TG-DTG, DSC and FTIR. The antioxidant, anticoagulant properties and cytotoxicity were tested to analyse and evaluate the quality of the film. The results state that the film has good thermal stability and through the results of FTIR it is proved that the film has functional groups of chitosan, gelatin, turmeric and other added components. And other results proved that the film is completely safe to be used as a food packaging material. Concerning/pertaining to the environmental issues and the effects of plastic films in human in terms of health and degradability conditions chitosan based films can bring about a change in the current packaging industry and the change could lead to better human and environmental health.
\end{abstract}

Keywords: Nanomaterials; Deproteinization; Deacteylation

\section{INTRODUCTION}

Food packages protect the food from spoilage and extend their shelf life and it is used to maintain the food in its best condition in terms of the colour, odour and form. Generally people use plastic made cling wraps and aluminium foil because of their elasticity, transparency and easy availability. Cling wraps are made up of plastic which is a major drawback because of its degradability and it causes a lot of health issues in patients who consume it and to the environment. Plastic is the major component which leads to the loss of marine life biodiversity and bioaccumulation. Cling wraps are plastic wraps made out of poly vinyl chloride and other chemicals which on infiltration with the food may lead to endocrine disruption which makes human prone to a lot of diseases like cancer especially breast cancer in females and reduction in sperm count in males. Styrofoam containers used for food packaging raise concerns for human health. Aluminium foils are used to wrap food in most of the houses but their safety on food is a question unanswered. our body can excrete a small concentration of aluminium efficiently but increased usage of aluminium foils have posed a serious threat to humans because of the high usage, aluminium at high concentration in human body may lead to brain damage which causes Alzheimer's disease and other health hazards. An ecofriendly biodegradable alternative is the need of the hour, especially after the Tamil Nadu government plastic ban on single use plastic consumers are looking for healthier alternatives to replace their current usage of plastic and related products. People have started using steel and copper bottles instead of plastic bottles and started using edible cutlery and steel everywhere but a packaging material for food is a much needed alternative people and industries are looking for.

Chitosan based food packaging material can be a better substitute for cling wraps and other packaging materials currently used. Chitosan is a Polysaccharide; it is made up of $\beta-(1-4)$-D-glucosamine and $\beta$-(1-4)-N-acetyl-D-glucosamine. Chitosan is obtained by alkaline deacteylation of chitin. Crustacean shells are made up of chitin. Crab, prawn and shrimp exoskeleton can be used because of their easy availability. Chitosan is a promising candidate to be used as a packaging material because of its antimicrobial and

*Correspondence to: Priya R Iyer, P G and Research Department of Biotechnology, Women`s Christian College, Chennnai, India, Tel: 9884160910; E-mail: brajuraj@yahoo.com

Received: July 20, 2019, Accepted: October 09, 2019, Published: October 16, 2019

Citation: Yashaswini M, Iyer P (2019) Chitosan Based Films Incorporated with Turmeric/Clove/Ginger Essential Oil for Food Packaging. J Nanomed Nanotech. 10:537. doi: 10.35248/2157-7439.19.10.537

Copyright: ( $) 2019$ Yashaswini M, et al. This is an open-access article distributed under the terms of the Creative Commons Attribution License, which permits unrestricted use, distribution, and reproduction in any medium, provided the original author and source are credited. 
biodegradable properties. And the film forming properties can be enhanced by using gelatin and essential oils which will add on to the properties of antimicrobial activities. Gelatin is a water soluble protein derived from partial hydrolysis of collagen, the byproducts obtained from the fishing industry like skin, bone, fins, scale and others are potential source for production of gelatin and exploration rather than disposable waste.

Turmeric, Ginger, Clove are widely used as spices in India, The essential oils of these three possess anti-inflammatory, antimicrobial, anti-viral, anti-oxidant properties. Because of all these exquisite qualities the oils are selected to be used as an additive to food packaging. All these extraordinary property possessing spices have been used in the Indian kitchen for food preservation for ages now; their ability to be used in food packaging is explored and compared in this research.

Palm leaf or the areca nut plates and cups are used as an alternative to plastic plates because of its biodegradability. They are disposable, light weight, thick and look great but there is a huge risk for the presence of contaminants on the plates which may play a key role to cause infections in humans. Antimicrobial coating may prevent or reduce the growth of microbes on these palm leaf cutlery which make it more efficient substitutes for plastic cutlery. Meat and fish products which are more susceptible to microbial contamination, even fruits and vegetables can be coated with the antimicrobial composites of the chitosan, gelatin and essential oils. Antimicrobial edible coatings are an effective alternative in active packaging materials to increase the safety of food for better commercialization of the food product. Consumers in and around the world want their food free from chemical preservatives but with an extended shelf life. So, efforts have been taken to develop new preserving and packing strategies, edible coating is one such strategy which is used to increase the post-harvest shelf life. Edible coating involves edible material which is applied to the product to form a thin layer on its surface which is natural replacement to the protective waxy coatings; it provides a barrier to moisture, oxygen. Spraying, dipping or brushing are the methods used for applying them onto the food. Edible coating creates a modified atmosphere which prevents spoilage during transport and storage.

\section{MATERIALS AND METHODOLOGY}

\section{Sample collection}

Crab shells were collected from the fish market of Chennai and Thanjavur area and the shells were sun dried for 2-3 days. And the essential oils of turmeric, clove and ginger was purchased from Amazon.

Extraction of chitosan: Chitosan was extracted by the process of demineralization, deproteinization and deacteylation [1].

Preparation of the film: Chitosan-gelatin films were made by modifications in the protocol [2]. After a lot of trial and error using chitosan, gelatin at different concentrations and temperature, the values of the concentrations of chitosan, gelatin and essential oils were standardized.

$0.4 \mathrm{~g}$ of chitosan is mixed with $1.2 \mathrm{~g}$ of gelatin. Both are added to $20 \mathrm{ml}$ of distilled water and $0.2 \mathrm{ml}$ of acetic acid and glycerol are added. Then $0.2 \mathrm{ml}$ of the essential oil (turmeric or clove or ginger) is added. All these are stirred well and heated in a water bath using a gas stove. After it boils and fumes come out the hot mixture is poured onto steel plates where we have applied coconut oil as a base. And the steel plates are allowed to dry at hot air oven for about 4-5 hours and after the film is dried it is removed from the oven and kept aside for 12 hours and then the film is carefully peeled out of the plate using a compass.

\section{Characterisation studies and analysis}

Measurement of film thickness: Film thickness is measured using a screw gauge at four random positions for each sample and two replicates were made per formulation.

Measurement of film transparency: Film transparency was measured by cutting the film into small rectangular sheets and placing them in a cuvette and using a colorimeter at $550 \mathrm{~nm}$. Film transparency was calculated using the equation: $\mathrm{T}(\%)=\mathrm{T}_{\mathrm{r}} / \mathrm{T}_{\mathrm{o}} \times$ 100 , where $T_{r}$ is the light intensity with film specimen in the beam and $T_{0}$ is the light intensity with no film specimen in the beam. All measurements are performed in triplicate.

Film stability: The film was checked for its stability after 1 month, the colour, texture odour and the nature of the film was evaluated and compared with the properties of the film when it was initially made.

Thermal property analysis: Thermogravimetric (TG-DSC), derivative thermogravimetric (TG-DTG) analyses and differential scanning colorimetry (NETZSCH DSC $_{204}$ ) were performed on the chitosan-turmeric and chitosan-clove essential oil incorporated films. Each film were heated up to 30 to $800^{\circ} \mathrm{C}$ at a heating rate of $10^{\circ} \mathrm{C} / \mathrm{min}$, under the nitrogen flow of $150 \mathrm{Ml} / \mathrm{min}$ The weight loss of samples was determined according to temperature.

FTIR analysis: Fourier-transform infrared spectroscopy (FTIR) analyses were performed by using a Perkin Elmer spectroscopy (Perkin Elmer, USA). The spectra were determined in a spectral range from $600 \mathrm{~cm}^{-1}$ to $4000 \mathrm{~cm}^{-1}$ with a resolution of $1.0 \mathrm{~cm}^{-1}$, using an attenuated total reflection (ATR) accessory with a diamond ATR crystal and The data were analysed by FTIR Spectrum software (Perkin Elmer).

Scanning electron microscopy (SEM) analysis: Structure and texture characterization is done by morphological examination of the films which was performed by scanning electron microscope (Quanta ${ }_{200}$ FEG SEM), it has a resolution of $1.2 \mathrm{~nm}$ gold particle separation on carbon substrate and a magnification of 10,000 to $60,000 \mathrm{X}$. In order to make the film conductive, the stub supporting samples were sputtered with gold and then the surface and crosssection morphologies of the film were observed [3,4].

Antimicrobial testing: Antibacterial testing: The bacterial cultures of E. coli, Klebseilla, Pseudomonas, Staphylococci spp, were taken and the UV sterilized films were placed after the bacterial culture is swabbed onto each plate the films (Turmeric and clove) are placed on the petriplate and incubated at $37^{\circ} \mathrm{C}$ and the growth is checked after 24 hours and the zone of inhibition is measured using a scale [5].

Antifungal testing: The fungal cultures of Penicillium spp., Candida albicans, Aspergillus flavus, Aspergillus niger were taken and The UV sterilised films were placed after the fungal culture was swabbed onto the media and the growth was checked after 24 hour incubation and the zone of inhibition was observed.

In vitro antioxidant activity: 1, 1-diphenyl-2picrylhydrazyl (dpph) radical scavenging: To evaluate the antioxidant property DPPH 
radical scavenging method was used. The antioxidant activity was compared with that of the natural antioxidant ascorbic acid. The concentrations of the extracts required to scavenge DPPH showed a dose dependent response. $25 \mathrm{mg}$ of each film was dissolved in $3 \mathrm{ml}$ of methanol, from that $2.8 \mathrm{ml}$ of the film extract solution is mixed with $0.2 \mathrm{ml}$ of $1 \mathrm{mM}$ methanolic solution of DPPH. The mixture was shaken vigorously and incubated at room temperature for $30 \mathrm{~min}$ in the dark. The reduction of the DPPH free radical was measured by reading the absorbance at $517 \mathrm{~nm}$ by spectrophotometer. The solution without any extract and with DPPH and methanol was used as the control. The experiment was replicated in three independent assays. Ascorbic acid was used as positive controls.

Anti-coagulation assay: Determination of PT (prothrombin time): Collection of blood and separation of plasma $100 \mathrm{ml}$ of blood was drawn from by vein puncture from a healthy individual. To the $9 \mu \mathrm{l}$ of blood $1 \mu \mathrm{l}$ volume of $3.8 \%$ trisodium citrate solution was added to avoid natural coagulation process. Immediately centrifuge for 15 min at $3000 \mathrm{rpm}$ to separate blood cells from plasma and to obtain pure platelet plasma (PPP). PT test was done using this PPP. All the tubes were tilted at an angle of $45^{\circ}$ for every 30 seconds to measure the clotting time. Clot formation was measured using a stop watch and this time is called as PT. the test was repeated in triplicates and the average was calculated [6].

In-vitro assay for cytotoxicity activity ( $\mathrm{mtt}$ assay): The cells $(1 \times$ $10^{5}$ /well) (VERO CELLS\& HEP2 CELLS) were plate in 24 well plates and incubated at $37^{\circ} \mathrm{C}$ with $5 \% \mathrm{CO}_{2}$ condition. After the cell reaches the confluence, media was removed from the wells carefully without disturbing the cells. The various sizes of the samples(the turmeric, clove and ginger chitosan based films) were added and incubated for 24 hours. after incubation, the samples was removed from the well and washed with phosphate buffered saline (pH-7.4) or MEM without serum. $100 \mu \mathrm{l} /$ well $(5 \mathrm{mg} / \mathrm{ml})$ of 0.5\% 3-(4,5-dimethyl-2-thiazolyl)-2,5-diphenyl-tetrazoium bromide (MTT) was added and incubated for 4 hours. After incubation, $1 \mathrm{ml}$ of DMSO was added in all the wells. The absorbance at 570 $\mathrm{nm}$ was measured with ELISA reader using DMSO as the blank. Measurements were performed and the concentration required for a 50\% inhibition (IC50) was determined [7]. The \% cell viability was calculated using the following formula:

$\%$ cell viability $=[($ Treated - Blank $) /($ control- blank $)] \times 100($ Yosie Andriani et al.)

Application of chitosan based films to packaging for chicken meat blocks: Small pieces of chicken was purchased from the meat shop nearby and they were covered with piece of the chitosan-based film and one more piece was covered with a plastic wrap which is used as a control and they were both kept in a Petri plate and the plate was wrapped with newspaper and kept in deep freezer for 7 days. Chitosan based films were also used like a cling wrap to cover the meat which was placed inside a glass and a plastic container and stored in the fridge for 7 days.

Coating of the film: Coating of the areca nut cups and plates: the film forming solution was poured onto the surface of the plate and cup and allowed to dry in the hot air oven for $40-50^{\circ} \mathrm{C}$ for 10 hours. Coating of the fruits and vegetables: Tomatoes and Amla are coated with this chitosan-gelatin film forming solution by dipping method and allowed to dry at room temperature.

Checking the water holding capacity after coating: The water holding capacity of the areca nut cups were evaluated by pouring hot water into them and they were allowed to stand with that water for 5-10 min and normal plain water was poured into another cup and that was compared for the water holding capacity and their stability.

\section{RESULTS AND DISCUSSION}

\section{Sample collection}

Crab shells were collected from the fish market of Chennai and Thanjavur area and the shells were washed with water for several times and sun dried for 2-3 days and the sample was further preceded for the extraction procedure [8].

The essential oils of turmeric, clove and ginger was purchased from Amazon (Figure 1 and 2).

\section{Extraction of chitosan}

This is a 3 step process: Demineralisation, Deproteinization, Deactelylation (Figure 3) [9].

\section{Preparation of the film}

The extracted chitosan was mixed with gelatin, essential oil, acetic acid and glycerol to obtain the film by using the process of heating and drying (Figures 4-6).

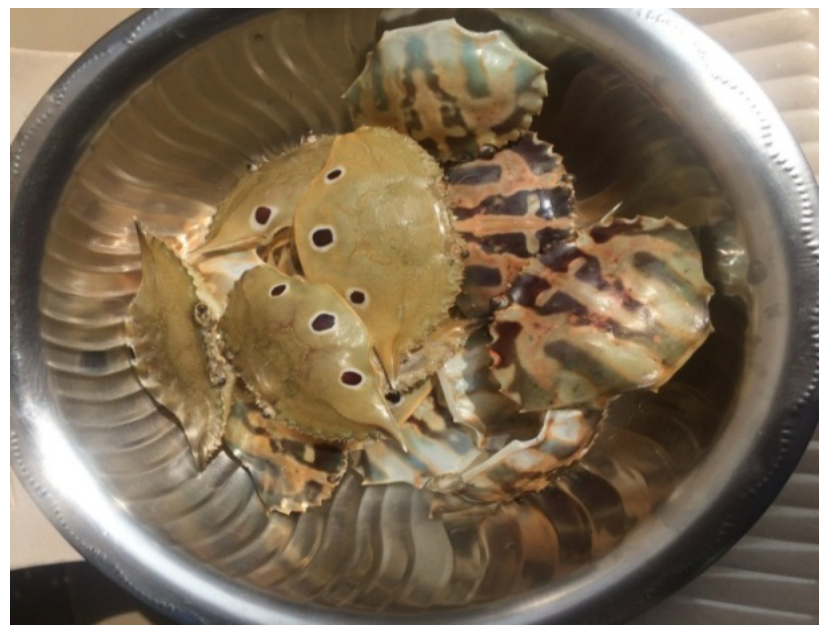

Figure 1: Collection of crab shells.

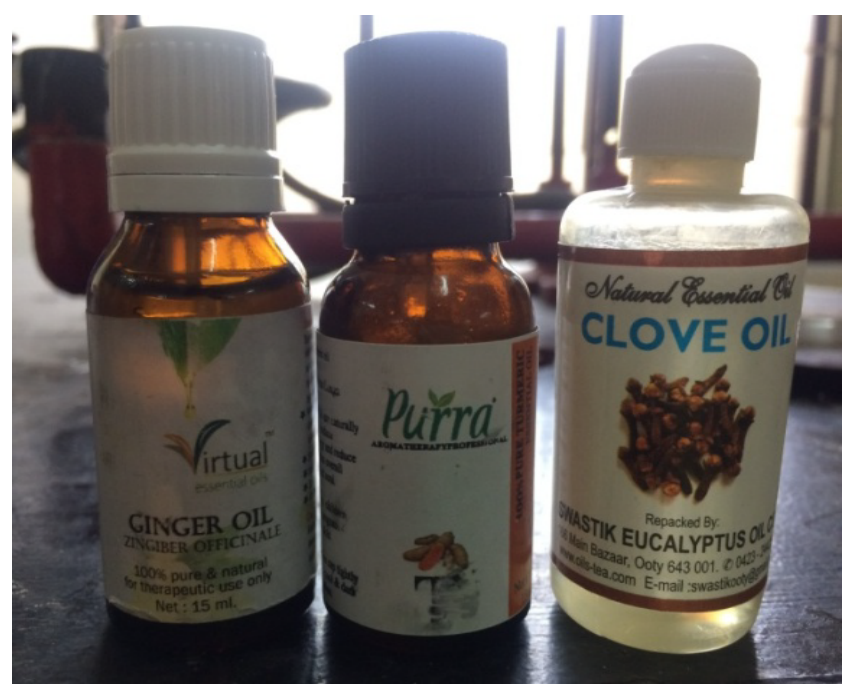

Figure 2: Purchased essential oil. 
Different combinations of the sample were tried to obtain a film of good quality varying concentrations of the sample and additives was used and then the correct concentrations required to obtain a good quality film was obtained (Table 1).

Standardised Chitosan solution $(1.0 \% \mathrm{w} / \mathrm{v})$ was obtained by dissolving $1.5 \mathrm{~g}$ of chitosan in $1.0 \%$ acetic acid $(150 \mathrm{ml})$ with stirring at $80{ }^{\circ} \mathrm{C}$ for $20 \mathrm{~min}$ to achieve complete dispersion. Glycerol (1.0\%) was then added as a plasticizer and stirred for 15 min and a combination of cinnamon and ginger essential oil was added [10].
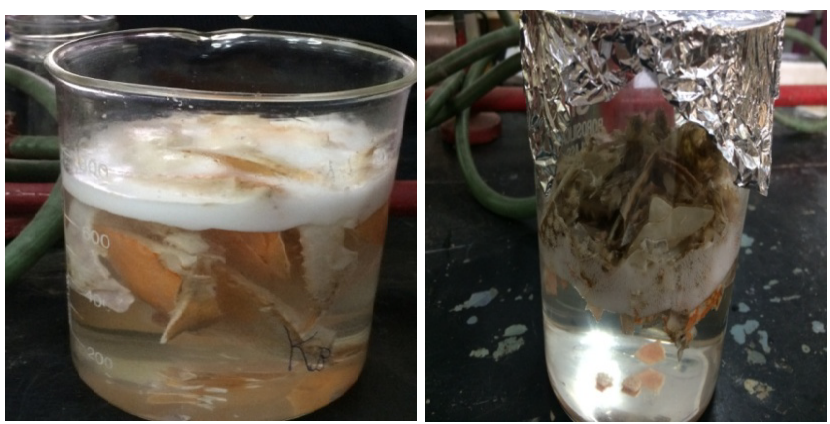

Figure 3: steps involved in the extraction of chitosan from crab shell.
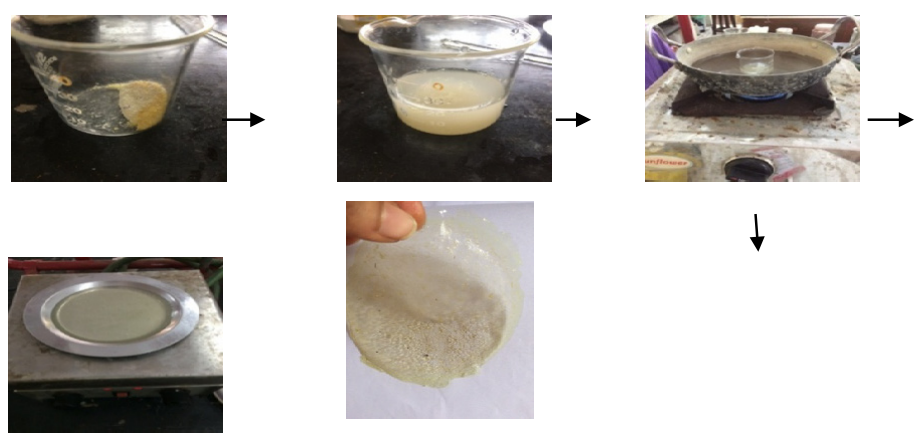

Figure 4: The procedure for production of the film by heating and drying.

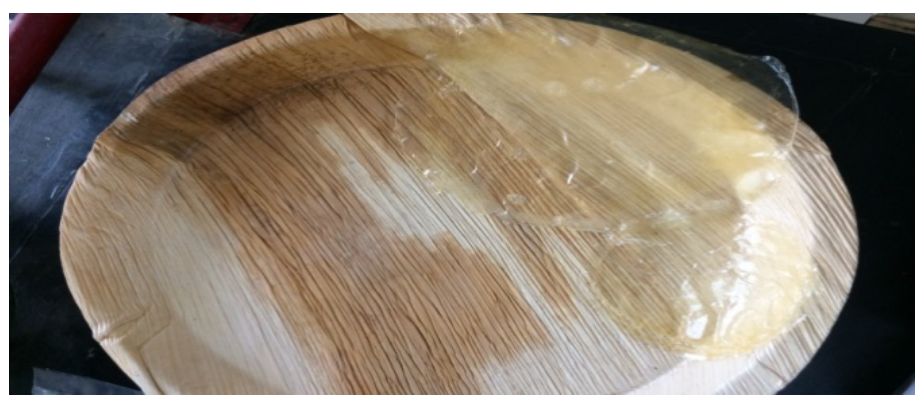

Figure 5: Chitosan based film with (Turmeric essential oil) at the concentration of $0.4 \mathrm{~g}$ Chitosan.

\section{Characterisation studies of the film}

Film thickness: The thickness of the film was found with the help of the screw gauge, an average of five different locations are selectedand the measurements were taken and it was found that the film was thick in the centre and thin towards the edges (Table 2). This may be due to influence of the steel plates which were used as a mould to obtain the films. The thickness of chitosanbased films incorporated with combined essential oil of cinnamon and ginger ranged from 0.068 to $0.105 \mathrm{~mm}$ when measured using a digital micrometer [11]. Thickness of the films was determined using a digital coating thickness gauge (Elcometer A300 FNP 23, Elcometer Instrument Ltd., Manchester, England) to the nearest $0.001 \mathrm{~mm}[12]$. This varying thickness is due to the change the procedure of film production. The procedure for film production varies with every work.

Film transparency: Film transparency is very important as it directly affects the appearance of wrapped food there is a decrease in transparency after the addition of Eos (turmeric/clove/ginger). The transparency of the film was evaluated using a colorimeter, the readings were taken at $550 \mathrm{~nm}$ and it was only $20 \%$. The edible film used for active packaging with cinnamon and ginger oil as additive had a transparency of $70 \%$ using a spectrophotometer. This may attribute to the color and thickness of the film [13].

Film stability: The films stored in the cupboard was seen after a month the films remained stable at normal conditions of temperature, humidity etc. The colour, texture and nature of the film was maintained at its original conditions but there were slight dry in appearance. This dryness was not very prominent to make changes into the films quality.

\section{Thermal property analysis}

These analyses were carried out to study the thermal properties of the film. The thermal stability of the sample was determined by instrument NETZSCH DSC ${ }_{204}$ in nitrogen atmosphere at the heating rate of $10^{\circ} \mathrm{C} / \mathrm{min}$. The Figures 7 and 8 represents the TGDSC thermogram of sample. The weight loss in the sample was observed with the onset of nearly $100^{\circ} \mathrm{C}, 250^{\circ} \mathrm{C}$ and $800^{\circ} \mathrm{C}$. The weight loss of about $5 \%$ at nearly $100^{\circ} \mathrm{C}$ in the sample was due to the removal of adsorbed water molecules on the surface of the film. The weight loss stages could be observed better in the DTG curves. The decomposition temperatures of both films are close to each other as around $280^{\circ} \mathrm{C}[14]$.

\section{Fourier transform infrared spectroscopy (FTIR)}

FTIR analysis was carried out to investigate the chemical interactions between chitosan, gelatin and the turmeric or other

Table 1: Standardisation of the concentration of chitosan and other additives.

\begin{tabular}{ccccc}
$\begin{array}{c}\text { Concentration of } \\
\text { Chitosan }(\mathrm{g})\end{array}$ & $\begin{array}{c}\text { Concentration of } \\
\text { Gelatine }(\mathrm{g})\end{array}$ & $\begin{array}{c}\text { Concentration of } \\
\text { Glycerol and acetic acid } \\
(\mathrm{ml})\end{array}$ & $\begin{array}{c}\text { Concentration Essential } \\
\text { oil }(\mathrm{ml})\end{array}$ & $\begin{array}{c}\text { Nature of the film } \\
\text { Very thin difficult to peel and poor } \\
\text { quality film }\end{array}$ \\
\hline 0.3 & 1 & 0.2 & 0.1 & $\begin{array}{c}\text { Transparent, easy to peel and good quality } \\
\text { film }\end{array}$ \\
\hline 0.5 & 1.2 & 0.4 & 0.4 & $\begin{array}{c}\text { Transparent but difficult to peel and good } \\
\text { quality film }\end{array}$ \\
\hline 0.6 & 1.4 & 0.5 & 0.5 & $\begin{array}{c}\text { Transparent but very difficult to peel and } \\
\text { average quality film }\end{array}$ \\
\hline
\end{tabular}



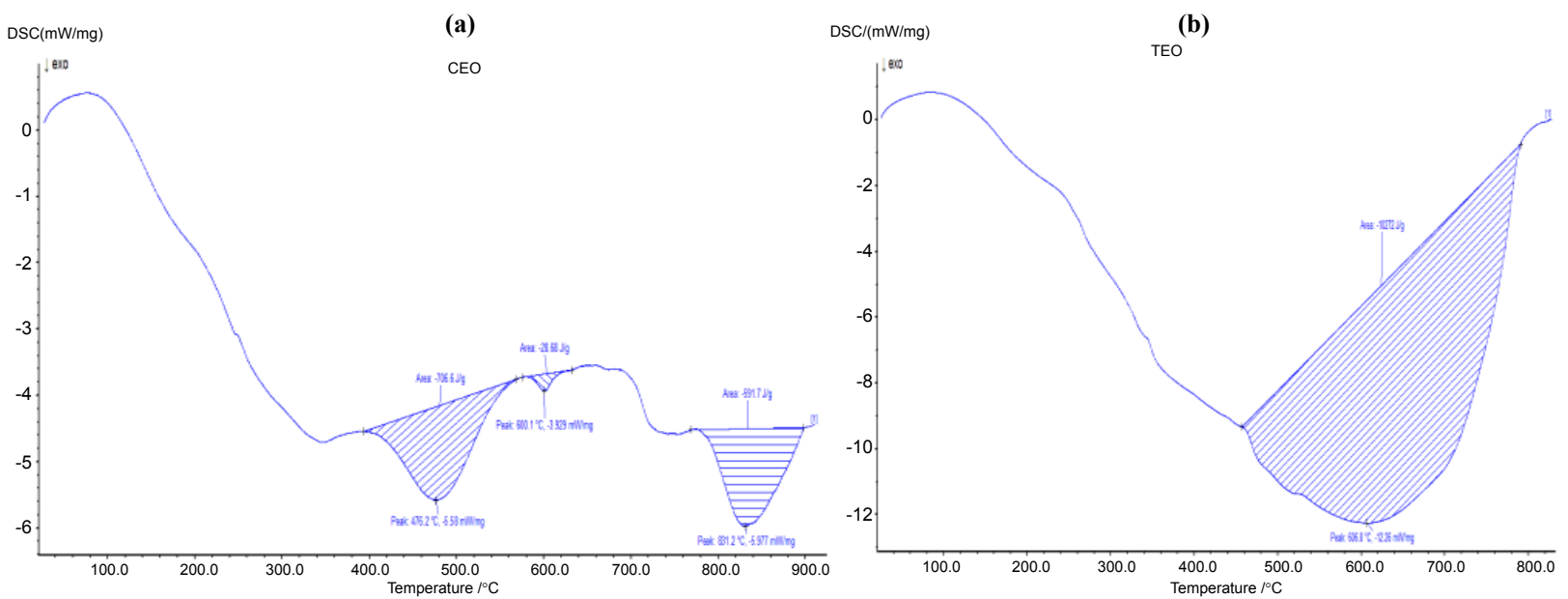

Figure 6: (a) DSC of the chitosan based film incorporated with clove (b) Turmeric essential oil.

Table 2: thickness of the chitosan based films.

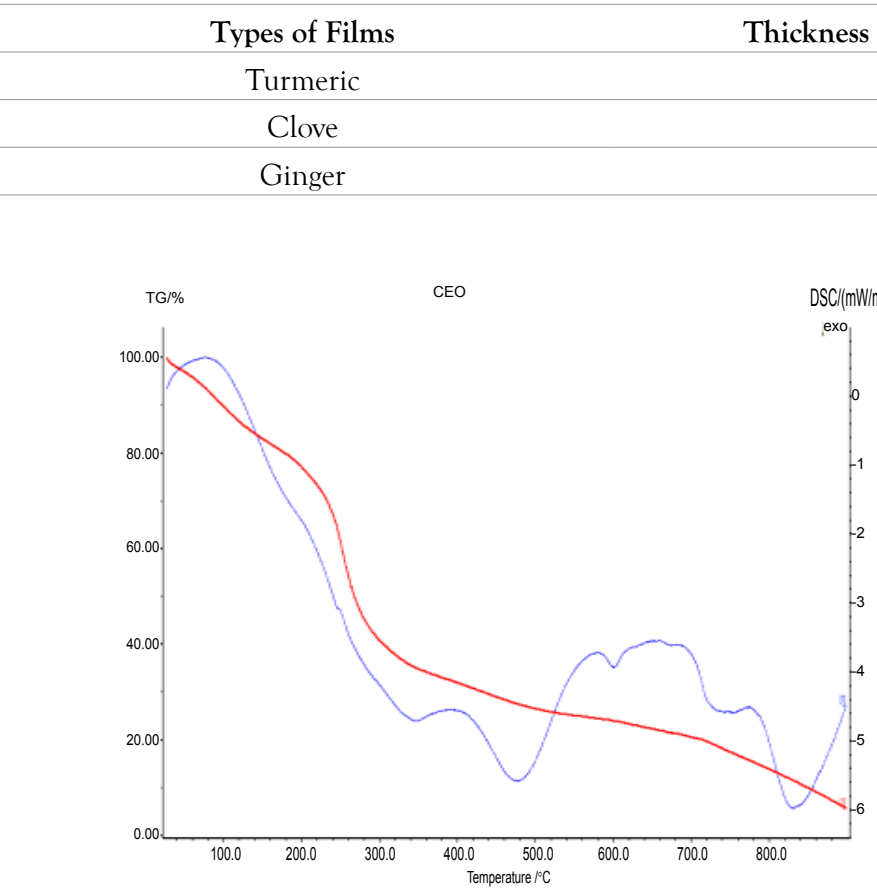

(a)
Thickness in the edges $(\mathrm{mm})$

$\begin{array}{ll}0.31 & 0.18 \\ 0.28 & 0.15 \\ 0.23 & 0.14\end{array}$

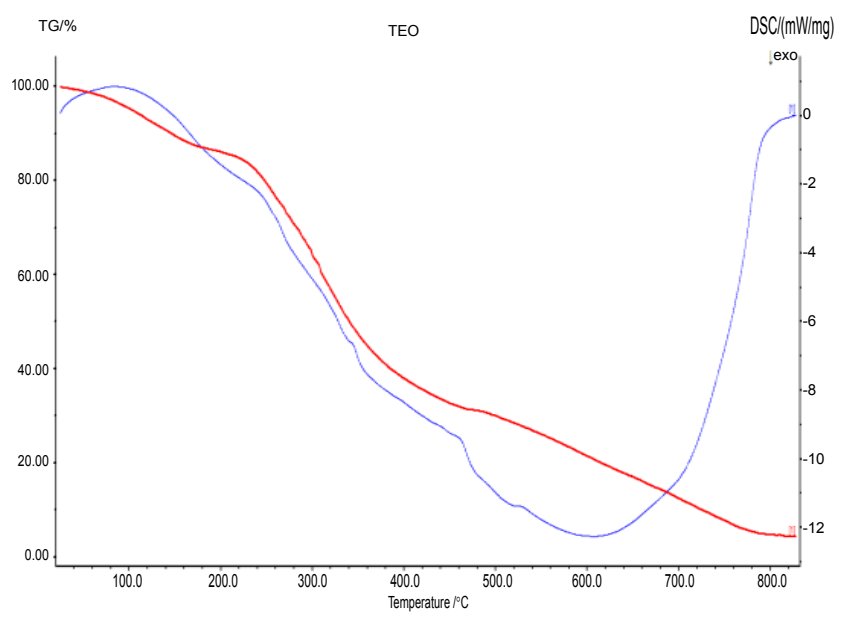

(b)

Figure7: (a) TG-DSC of the chitosan based film incorporated with clove. (b) Turmeric essential oil.

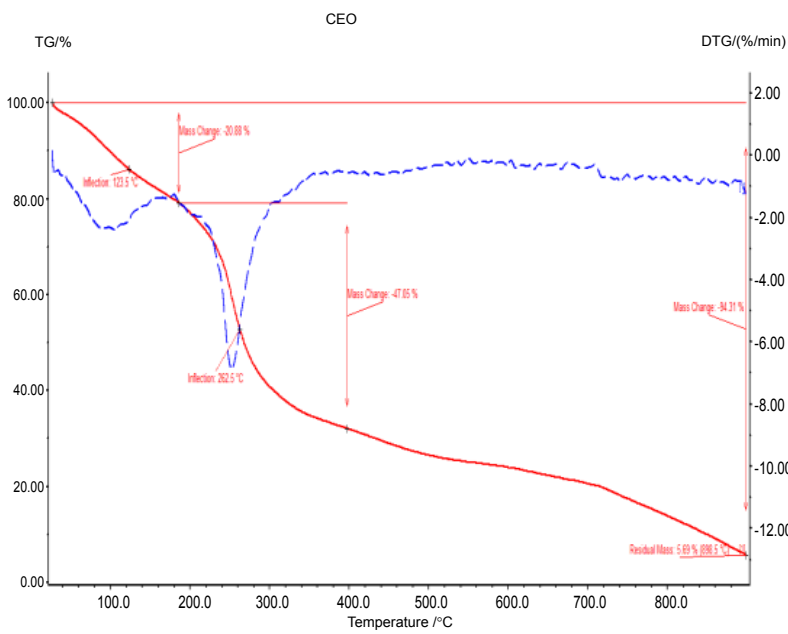

(a)

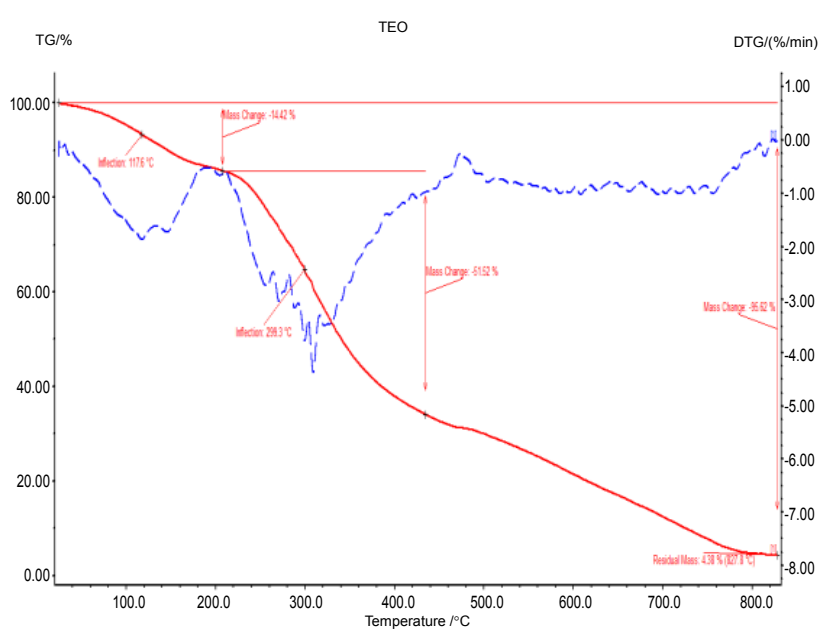

(b)

Figure 8: (a) TG-DTG of the chitosan based film incorporated with clove. (b) Turmeric essential oil. 
oil additives and to identify the functional groups (Figure 9). The peaks of the CEO (clove essential oil) \&TEO (turmeric essential oil) incorporated chitosan film show the characteristic of pure chitosan film. A broad absorption range of 3200 and $3550 \mathrm{~cm}^{-1}$ is due to overlapping of hydroxyl group and amino group. Stretching vibration was observed in both films. The peaks at $2928 \mathrm{~cm}^{-1}$ and $2287 \mathrm{~cm}^{-1}$ were due to the $\mathrm{CH} 2$ - stretching. In both spectrums, it can be said that the absorption band at $1632 \mathrm{~cm}^{-1}$ belongs to amide I. Peaks at $1544 \mathrm{~cm}^{-1}$ represent the N-H (amide II band) of chitosan carbon chains. The peak at $1241 \mathrm{~cm}^{-1}$ in TEE incorporated films was assigned to the C-O stretching vibration of benzene ring, which was regarded as a characteristic peak belonging to cucurcuminoids showed major peaks at approximately $3276.35 \mathrm{~cm}^{-1}$ (amide-A, N-H stretching), $2928.86 \mathrm{~cm}^{-1}$ (amide-B, C-H stretching), $1632.65 \mathrm{~cm}^{-1}$ (amide-I, $\mathrm{C}=\mathrm{O}$ stretching), $1544.03 \mathrm{~cm}^{-1}$ (amide-II, N-H bending), and $1241.91 \mathrm{~cm}^{-1}$ (amide-III, C-N and N-H stretching). The results have matched with the values of the similar research done $[15,16]$.

\section{SEM analysis}

SEM images of surface and cross-sections of chitosan based films had a compact and uniform surface, indicating that a wellorganized structure was formed. And through magnification in $6000 \mathrm{X}$ we have found the average grain size to be $564.07 \mathrm{~nm}$ in case of films incorporated with CEO and $459.4 \mathrm{~nm}$ in case of films incorporated with TEO. Additionally, the cross-section analysis of the film states that it has an even and dense structure without flaws or pores. Additionally cross section analysis have given the thickness of the film as $240.23 \mu \mathrm{m}$ (CEO) and $220.2 \mu \mathrm{m}$ (TEO)
(Figure 10-12). The results suggested that the chitosan and gelatin were dispersed evenly in the film formed $[17,18]$.

\section{Antimicrobial testing}

Chitosan based films showed good zone of inhibition against all the bacterial cultures of E. coli, Klebseilla, Pseudomonas, staphylococci spp (Table 3) and fungal cultures of Penicillium spp., Candida albicans, Aspergillus flavus, Aspergillus niger (Table 4) and the zone of inhibition was better for CEO(Clove essential oil based chitosan films) than TEO (Turmeric Essential oil based chitosan films).

In vitro antioxidant activity: 1,1-diphenyl-2picrylhydrazyl (DPPH) radical scavenging: The test revealed that the films have good antioxidant activity, and it was calculated that TEO film has about 56\% and CEO film has about 64\% [19]. Antioxidant mode of action might be related to the primary amino groups of chitosan forming a stable flurosphere with volatile aldehydes, which is derived from the breakdown of fats during oxidation [20] Furthermore, the oxygen barrier properties of chitosan film/ coating might also have contributed to controlling lipid oxidation [21].

Anti-coagulation assay: Anticoagulant activity of turmeric and clove films is shown in Figures 13-16. The results state that the films do not have anticoagulation properties, and it will be safe to use on humans as it will not affect the coagulation property of blood. Other studies have demonstrated the sulfated chitosan from D. scortum having good anticoagulant activity due to the presence of sulfate group [22]. The anticoagulant property is not observed in

Table 3: Antibacterial activity of the films.

\begin{tabular}{|c|c|c|c|}
\hline S.no. & Bacterial Cultures & $\begin{array}{l}\text { Teo-Zone of inhibition in } \\
\mathrm{mm}\end{array}$ & $\begin{array}{l}\text { Ceo-zone of inhibition in } \\
\mathrm{mm}\end{array}$ \\
\hline 1. & Klebsiella spp & $15 \mathrm{~mm}$ & \\
\hline 2. & Staphylococcus spp & $15 \mathrm{~mm}$ & $15 \mathrm{~mm}$ \\
\hline 3. & Escherchia coli & $15 \mathrm{~mm}$ & $13 \mathrm{~mm}$ \\
\hline 4. & Streptococcus spp & $15 \mathrm{~mm}$ & $15 \mathrm{~mm}$ \\
\hline 5. & Bacillus spp & $15 \mathrm{~mm}$ & $13 \mathrm{~mm}$ \\
\hline
\end{tabular}
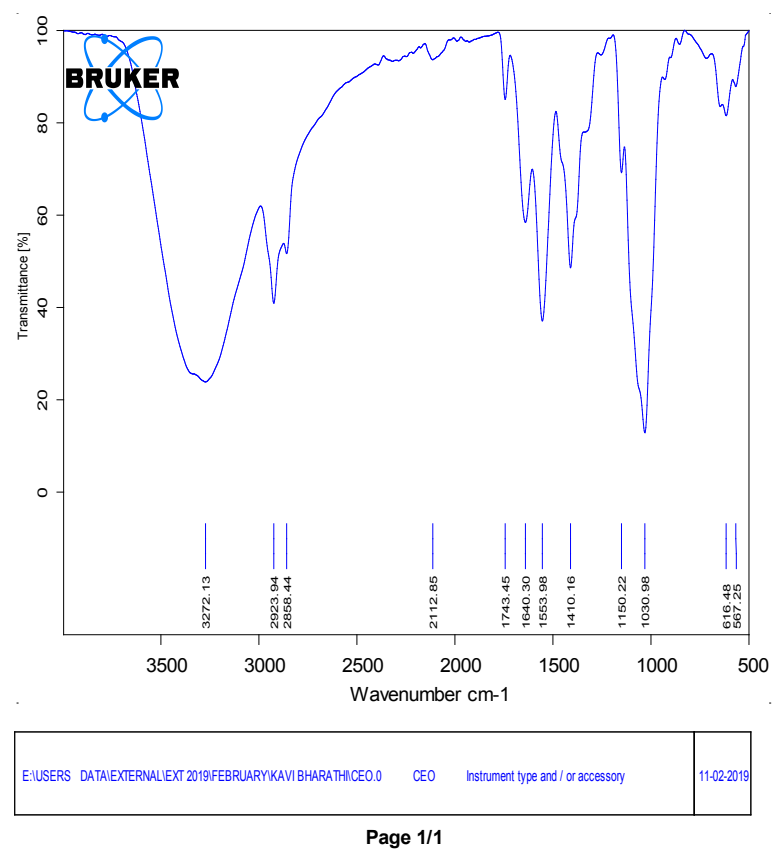

(a)
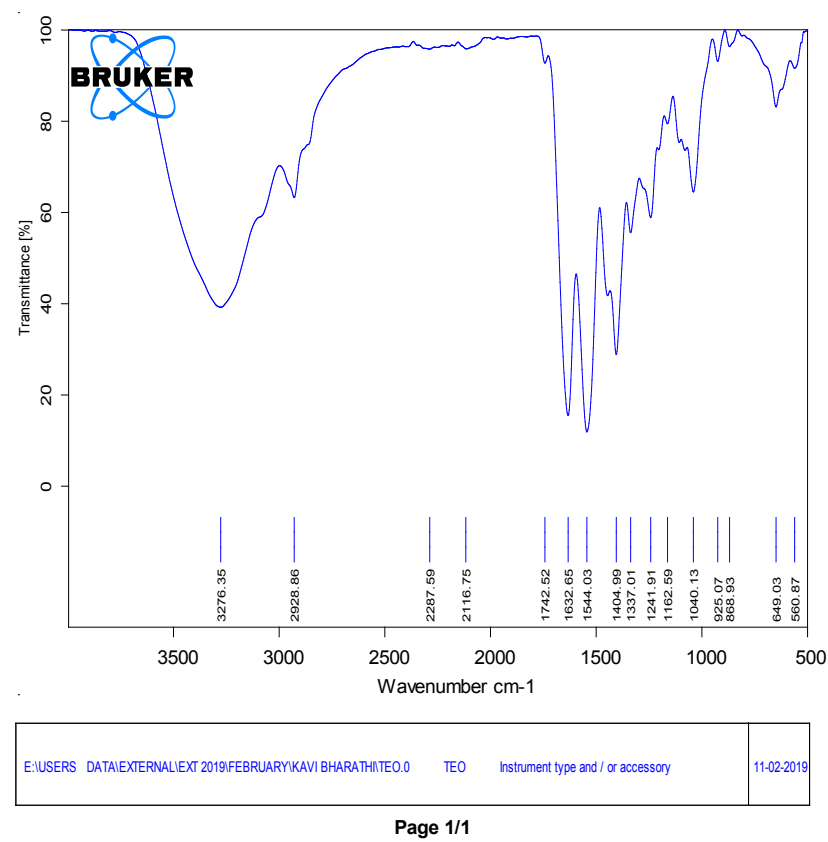

(b)

Figure 9: (a) A FTIR analysis for Chitosan based films incorporated with turmeric essential oil and (b) clove essential oil. 

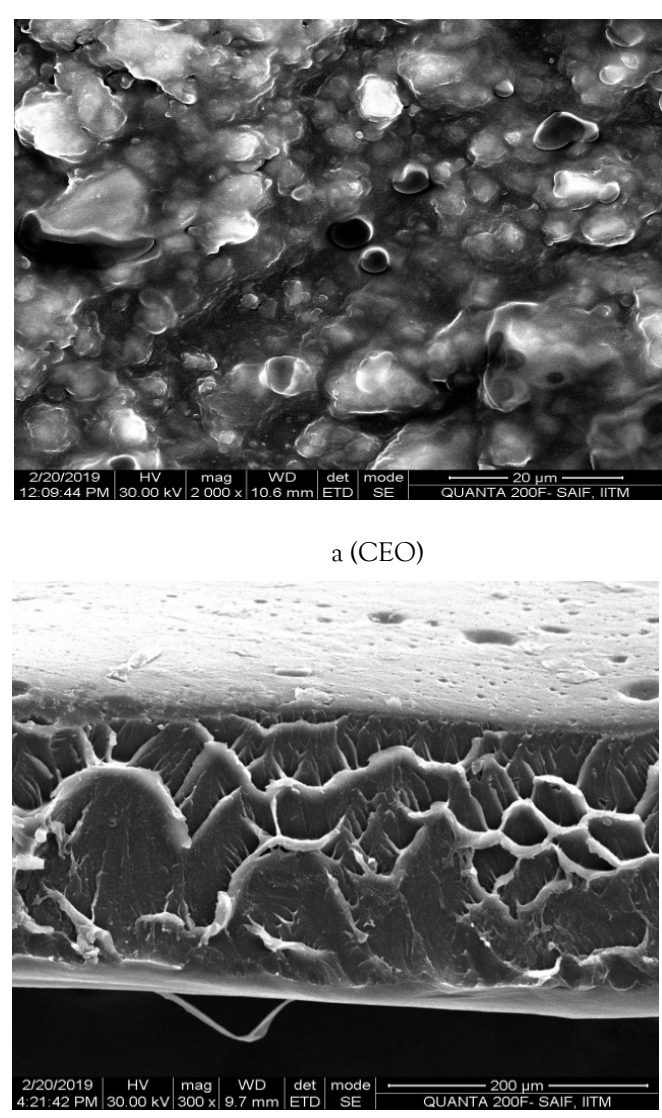

c (CEO)

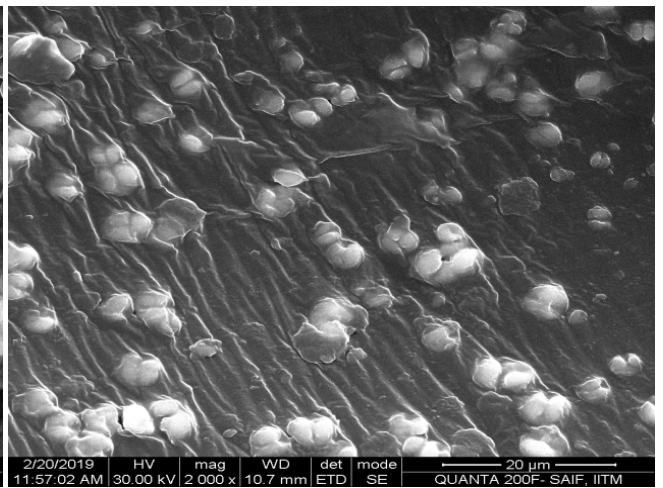

$\mathrm{b}$ (TEO)

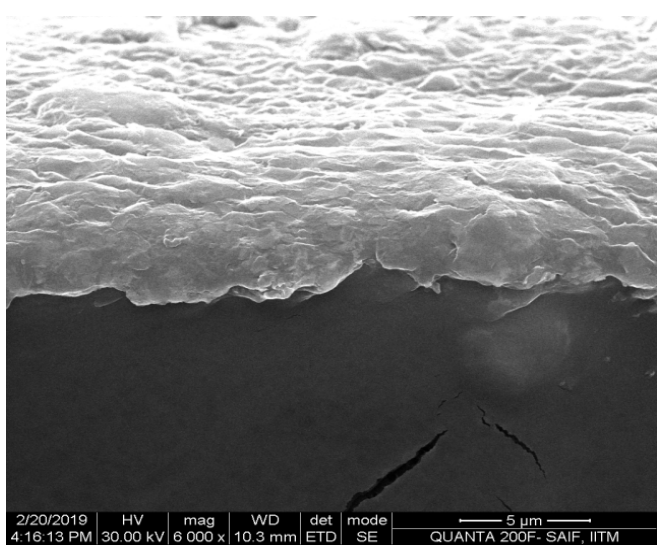

$\mathrm{d}(\mathrm{TEO})$

Figure10: Represents the SEM micrographs of the surface and cross section of the film.

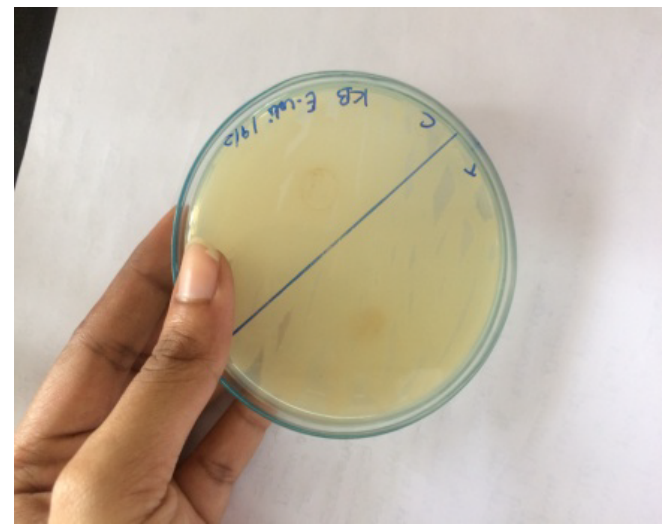

a

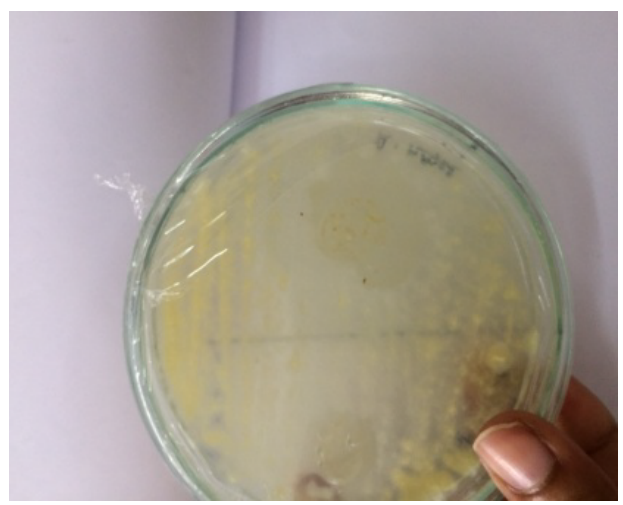

$\mathrm{C}$

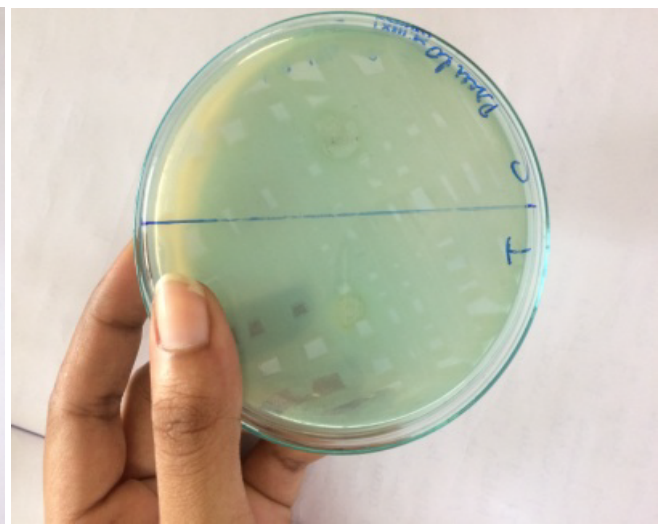

$\mathrm{b}$

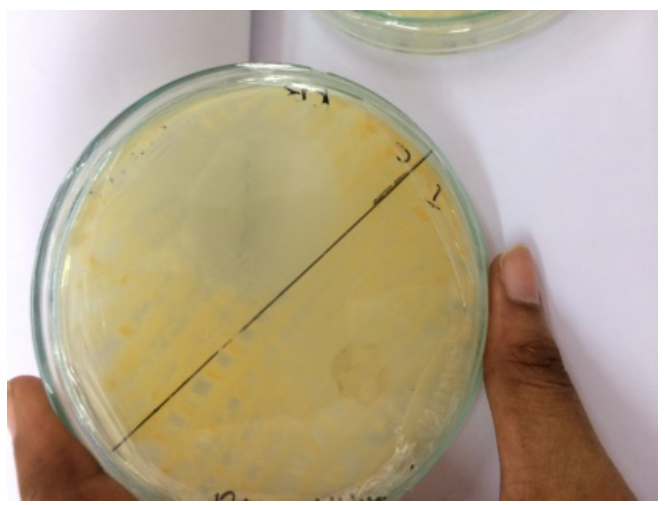

d

Figure 11: Antibacterial activity E. coli (a) and Pseudomonas spp. (b) showing zone of inhibition. Antifungal activity against Penicillium spp. (c) and Aspergillusniger (d). 


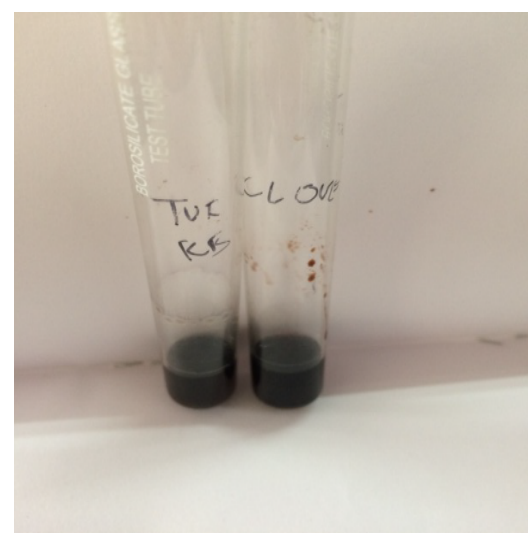

(a)

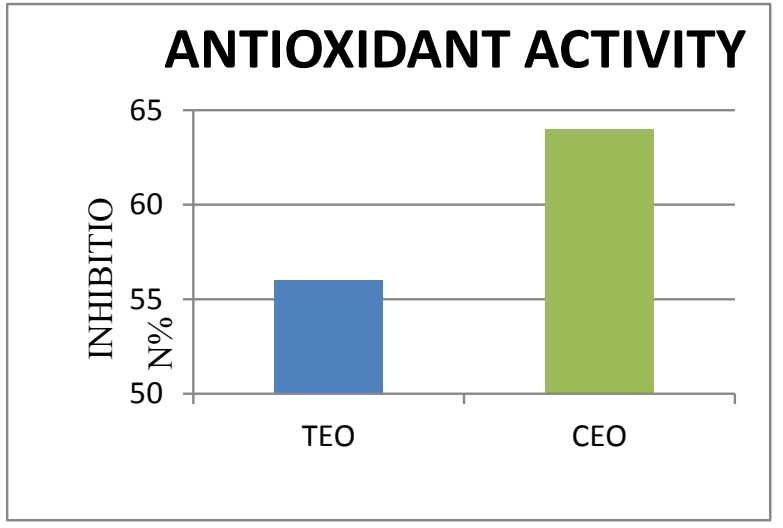

(b)

Figure 12: (a) DPPH Assay for turmeric and clove films (b) The \% Inhibition of the TEO and CEO.

Table 4: Antifungal activity of the films.

\begin{tabular}{|c|c|c|c|}
\hline S. No. & Fungal Cultures & Teo-Zone of inhibition in mm & Ceo-zone ofinhibition in mm \\
\hline 1. & Penicillum spp & $18 \mathrm{~mm}$ & $22 \mathrm{~mm}$ \\
\hline 2. & Aspergillus niger & $17 \mathrm{~mm}$ & $21 \mathrm{~mm}$ \\
\hline
\end{tabular}

Table 5: \% of cell viability.

\begin{tabular}{|c|c|}
\hline Sample & Cell viability\% \\
\hline Clove & 79.83 \\
\hline Turmeric & 65.47 \\
\hline Ginger & 48.23 \\
\hline
\end{tabular}

the film produced in our study may be because of the binding of other additives would have marked an influence.

In-vitro assay for cytotoxicity activity (MTT assay): The results of the MTT assay reveals that the films do not possess good anticancer property but they are non-toxic to cells which proves that they can be safely used as a food packaging material (Table 5). Cytotoxicity assay against hep2G Cells was carried out for various chitosan nanoparticles [21].

Application of chitosan based film for food packaging: After wrapping the meat with the film they were stored in deep freezer and the conditions were observed after 7 days of storage and it was found that the meat remained fresh without any change in colour, texture, odour and form. This proves that the film is able to maintain the desired environment for storage and can be efficiently used as a food wrapper. They used this technique of food preservation to preserve pork where the pork remained fresh for 7 days [22].

Usage of the film as a cling wraps: The film has good stretch ability so; it was used as cling wrap to cover the meat in a container because most of the meat in the market comes in boxes covered with a cling wrap at the top. These containers were left in the freezer of the fridge and stored for 7 days and it was found that the meat remained fresh after 7 days of storage without any contamination or structural deformities.

Coating of the film: Areca nut plates are the most commonly used alternatives for plastic plates and cups but because they are prone to microbial spoilage their shelf life is reduced to overcome this hurdle we have come up with the solution of coating of the areca nut cutlery with the film forming solution of chitosan (Figure 17). The film was coated on the areca nut plates and cups and after coating they had good odour and the cups, when tested for its

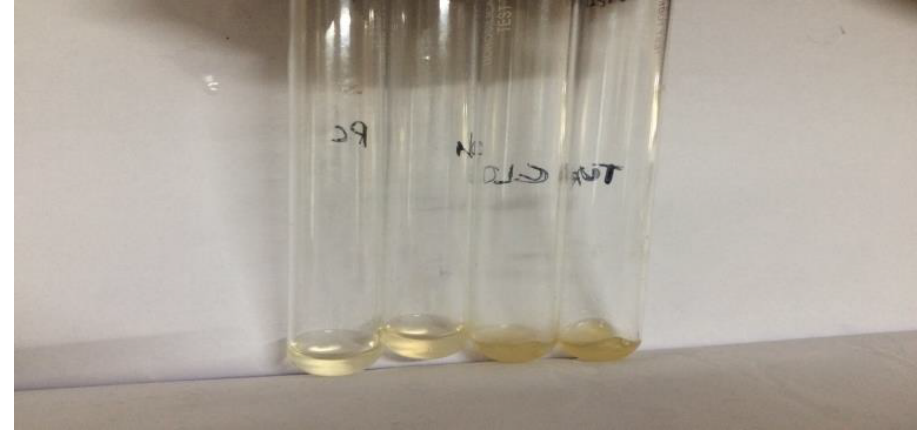

Figure 13: anticoagulant activity of turmeric and clove films.

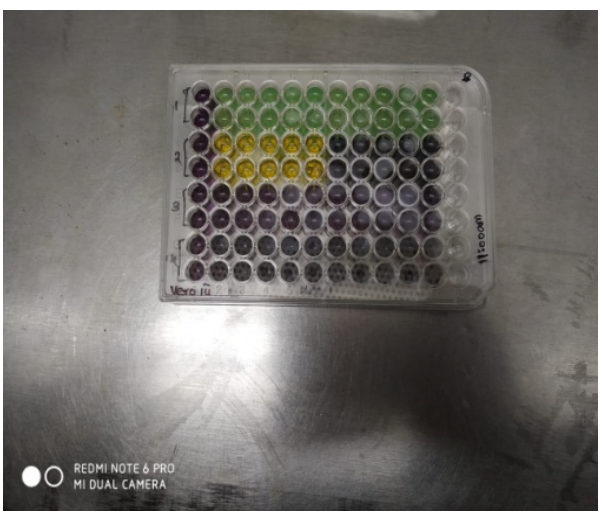

Figure14: MTT ASSAY: the well with the samples (clove, turmeric, ginger).

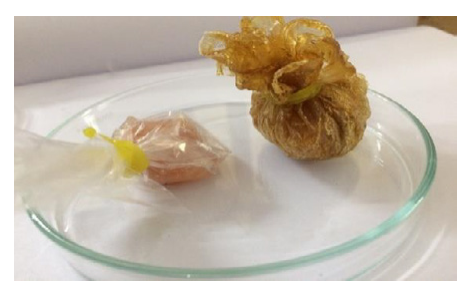

(a)

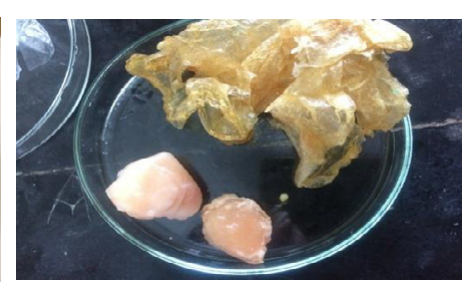

(b)
Figure15: Chitosan based film used as a meat wrapper for storage in deep refrigeration along with a plastic wrapper which is used as control. (a) $1^{\text {st }}$ day of storage (b) $7^{\text {th }}$ day of storage.

holding capacity with hot water it did not leak and was very stable To reduce the growth of microorganisms like gram positive and 


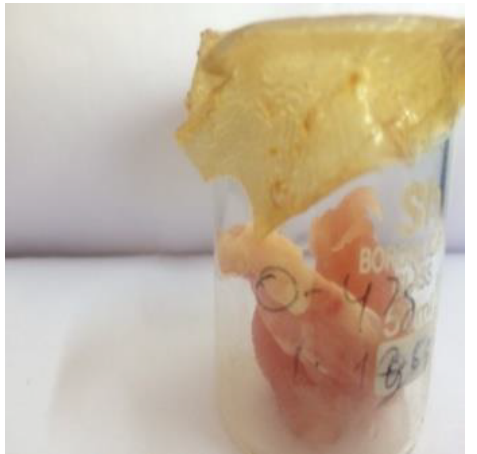

(a)

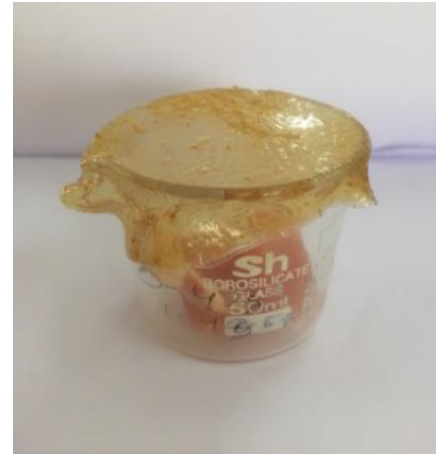

(b)
Figure 16: Chitosan based films used a cling wrap to package meat.

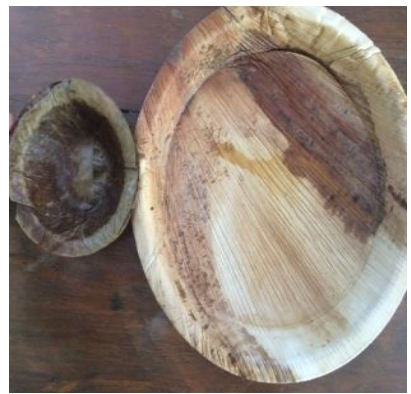

Figure 17: Areca nut plates and cups coated with the film.

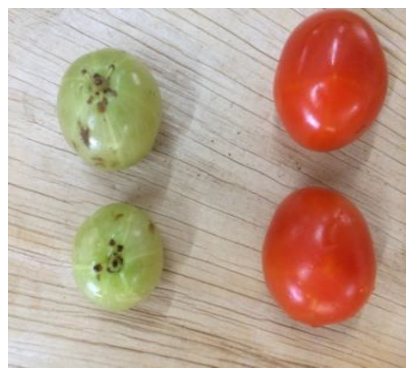

Figure 18: Coating of fruits and vegetables.

gram negative bacteria, yeast and mould growth antimicrobial food packaging.

Coating of fruits and vegetables can be done instead of wax coating to preserve the fruits and vegetables the coated tomatoes remained fresh but non coated one got spoiled. But the amla both the coated and not coated spoiled within 2 days of storage, this is because the tomatoes were fresh and amla was already in the starting state of spoilage, where the microbial load is difficult to control (Figure 18).

Checking the water holding capacity after coating: The water holding capacity of the areca nut cups were evaluated by pouring hot water into them and they were allowed to stand with that water for 5-10 min and normal plain water was poured into another cup and that was compared for the water holding capacity and their stability. It was observed that the cups were holding water without any leakage for $10 \mathrm{~min}$. but when the hot water is contained in them for long time the coating is disrupted so, liquid food is not a preference for these coated cutleries (Figure 19).

\section{DISCUSSION}

Chitosan and encapsulation of chitosan has been widely used in the field of pharmaceuticals and drug delivery. Using chitosan

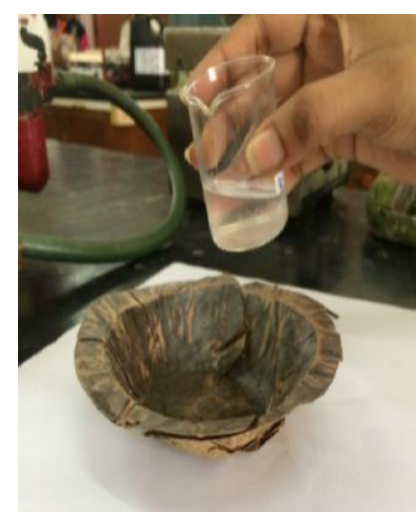

Figure 19: Checking the water holding capacity after the coating.

blended with gelatin produce a film with excellent properties which are looked in a packaging material. chitosan extracted from crab shells which are a waste in the sea food industry makes it an inexpensive option.

\section{CONCLUSION}

Chitosan based films are the dynamic solution to the current need of biodegradable, active packaging material for food. The film's antimicrobial activities impart its usage as a packaging material as it will be able to effectively control the contamination or spoilage of the food. It will be not only a solution for the plastic pollution but will also be a healthier alternative for usage in the food packaging industry. Chitosan naturally has antimicrobial property; this property is enhanced by adding essential oils and gelatin. All these together form an excellent biomaterial which can be used for food packaging. They can mainly be used for meat packaging and can also be used for coating of areca nut cutleries and fruits and vegetables to increase their shelf life. All the characteristics which have been found through the analysis of FTIR, Thermogravimetric analysis, SEM and antimicrobial, anticoagulant, antioxidant and anticancer cell cytotoxicity reveals that the film is an eligible candidate for food packaging.

\section{REFERENCES}

1. EmrahTorlak B, enAkınEving G, Ozen I, Kalaycıoglu Z. Antimicrobial and physica:erties of chitosan films incorporated with turmeric extract, Int J Biol Macromol. 2017;03:174.

2. Maniglia D, Tapia-Blacido P. Turmeric dye extraction residue for use in bioactive film production:Optimization of turmeric film plasticized with glycerol, LWT. Food Science Technol. 2015;1187-1195.

3. Lin Ye, Lianqiang Wu, Zhang P, Xia Y, Wang Y. Physical characterisation and Pork Packaging Application of Chitosan Films Incorporated with Combined Essential oils of Cinnamon and Ginger. Food Bioprocess Technol. 2016;1883-1888.

4. Mustafa MK, Nasreen Z. Improved biodegradable radiation cured polymeric film prepared from Chitosan-Gelatin Blend. J Appl Chem. 2016;16.

5. Amaro-Reyes A, García-Almendárez BE, Regalado-González C, Angélica CP, Jorge J, García ME, et al. Physical, Structural, Barrier, and Antifungal Characterization of Chitosan-Zein Edible Filmswith Added Essential Oils. Intern J Mol Sci. 2016.

6. Sahoo CJ, Kumar M, Singh TP. Development of chitosan 
based edible films: process optimization using response surface methodology. J Food SciTechnol. 2015;52(5):2530-2543.

7. Rezaei M, Razavi SH, Ojagh SM, Hosseini SMH. Development and evaluation of a novel biodegradable film made from chitosan and cinnamon essential oil with low affinity toward water. Food Chem. 2010;122:161-166.

8. Beltrán A, Valdés A, Garrigós MC, Ramos M. Gelatin-Based Films and Coatings for Food Packaging Applications, Coatings. 2016.

9. Valdés ABA, Garrigós MC. State of the Art of Antimicrobial Edible Coatings for Food Packaging Applications, coating. 2016.

10. Ding D, Shao H, Peng Q, Huang Y, Yao Y. Antibacterial Acti vityandPhysicalPropertiesofFishGelatin-Chitosan Edible Films Supplemented with D-Limonene. Intern J Pol Sci. 2016.

11. Tabari M. Investigation of Carboxymethyl Cellulose(CMC) on Mechanical Properties of Cold Water Fish Gelatin Biodegradable Edible Films.Foods. 2017.

12. Peñaa C, Mondragon I, Algara I, Martuccib J, Mondragona G, Ruseckaite R, et al. Gelatin films. Renewable resource for food packaging. Novo Sci Pub. 2009.

13. Gadgey KK. Studies on extraction method of chitin from crab shell and investigation of its mechanical properties. Intern J Mech Eng Tech. 2017;8(2):220-231.

14. Suppakul P, Sonkaew P, Boonlert R, Luckanatinvong V, Buaphet W. Efficacy of superior antioxidant Indian gooseberry extract incorporated edible Indian gooseberry puree/ methylcellulose composite films on enhancing the shelf life of roasted cashew nut. Food Control. 2016;69:51-60.

15. Ho J, Wai W, Chan Y, Bun T, Randy N, Cheung CF, et al. Chitosan: An Update on Potential Biomedical and Pharmaceutical Applications Mar. Drugs. 2015;13:5156-5186.

16. Bustillos A, Otoni CG, Mattoso LHC, Lorevice MV, Moura MR, Azeredo RJH, et al. Recent Advances on Edible Films Based on Fruits and Vegetables-A Review, comprehensive Reviews in Food science and food safety, 2017.

17. Lianqiang Wu, Lin Ye, Zhang P, He S, Xia Y, Wang Y. Physical Characterization and Pork Packaging Application of Chitosan Films Incorporated with Combined Essential Oils of Cinnamon and Ginger. Food Bioprocess Technol DOI 10.1007/s11947016-1833.

18. Quesada J, Sendra E, Navarro C, Sayas-Barbera E. Antimicrobial Active Packaging including Chitosan Films with Thymus vulgaris L. Essential Oil for Ready-to-Eat Meat. Foods. 2016;5(3).

19. Peng F, Bian J, Xu JD, Yue PP, Sun RC, Hu YJ, et al. Composite Film Based on Pulping Industry Waste and Chitosan for Food Packaging. Materials. 2018;13:11(11).

20. Chegu K, Mounika K, Rajeswari M, Vanibala N, Sujatha P, Sridurga $\mathrm{P}$, et al. In vitro study of anticoagulant activity of some plant extracts. WJPPS. 2018;7(5):904-913.

21. https://www.ncbi.nlm.nih.gov/pmc/articles/PMC4711446/ pdf/13197_2015_Article_2018.pdf.

22. http://www.imedpub.com/scholarly/food-biotechnologyjournals-articles-ppts-list.php 